\title{
Effects of testosterone and 17 $\beta$-estradiol on angiotensin-induced changes in tyrosine kinase activity in the androgen-independent human prostate cancer cell line, DU145
}

\author{
KAMILA DOMIŃSKA ${ }^{1}$, ANTONI KOWALSKI ${ }^{2,3}$, TOMASZ OCHĘDALSKI ${ }^{1}$ and ELŻBIETA RĘBAS ${ }^{2}$ \\ Departments of ${ }^{1}$ Comparative Endocrinology and ${ }^{2}$ Molecular Neurochemistry, \\ Medical University of Lodz, 92-215 Lodz, Poland
}

Received April 19, 2017; Accepted August 24, 2017

DOI: $10.3892 / \mathrm{ijmm} .2017 .3149$

\begin{abstract}
Angiotensin II (AngII), the main peptide of the renin-angiotensin system (RAS), is involved in the proliferation of different types of cells, normal and pathological as well. The protein tyrosine kinases (PTKs) play an important role in the growth, differentiation and apoptosis of cells. AngII action depends on the hormonal milieu of the cell, and on sex steroid influence. Angiotensin 1-7 (Ang1-7), metabolite of AngII, shows opposite action to AngII in cells. The present study aimed to examine the influence of $17 \beta$-estradiol and testosterone on AngII and Ang1-7 action on PTK activity in androgen-independent humane prostate cancer cell line DU145. Cell cultures of human prostate cancer DU145 cells were used as a source of PTKs. Cultures were exposed to different concentrations of AngII $\left(5 \times 10^{-11}\right.$ to $\left.5 \times 10^{-9} \mathrm{M}\right)$. The incubation with hormones lasted $15 \mathrm{~min}$ to limit the genomic effects of steroids. In the phosphorylation reaction, we used $\gamma^{32} \mathrm{P}$-ATP as a donor of phosphate and a synthetic peptide, Poly(Glu, Tyr) (4:1), as a substrate. The specific activities of PTKs were defined as pmol of ${ }^{32} \mathrm{P}$ incorporated into $1 \mathrm{mg}$ of exogenous Poly(Glu, Tyr) per minute (pmol/mg/min). Our findings suggest that testosterone and $17 \beta$-estradiol may change the effects of angiotensins in a rapid non-genomic way, probably via membrane-located receptors. The most significant change was caused by testosterone, whose effect was most significant on changes caused by Ang1-7. AngII-induced changes in phosphorylation appeared to be insensitive to the presence of testosterone, but were modified by $17 \beta$-estradiol.
\end{abstract}

Correspondence to: Dr Elżbieta Rębas, Department of Molecular Neurochemistry, Medical University of Lodz, Mazowiecka Street 6/8, 92-215 Lodz, Poland

E-mail: elzbieta.rebas@umed.lodz.pl

Present address: ${ }^{3}$ Department of Molecular Biology and GeneticsDANDRITE, Aarhus University, 8000 Aarhus C, Denmark

Key words: angiotensin II, angiotensin 1-7, DU145, human prostate cancer, tyrosine kinases, angiotensin receptors

\section{Introduction}

The renin-angiotensin system (RAS) is known for the control of blood pressure and fluid homeostasis but also for its engagement in the development of prostate cancer (1). The main peptide of RAS, angiotensin II (AngII) acts via G-protein coupled AT1 and AT2 receptors (AT1R, AT2R). AT1R is present in the healthy prostate and is upregulated in prostate cancer cells $(2,3)$. Expression of AT2R is commonly lower than AT1R and its upregulation is related to tissue damage, due to its role in protection and regeneration of tissues (4). AngII may transmit signals through protein tyrosine kinases (PTKs), enzymes involved in cell proliferation as well as cell apoptosis (5). Moreover, inhibitors of tyrosine kinases have been recently developed as molecular-targeted drugs for prostate cancer (6). The physiological effects of AngII are dependent on the receptor type. Vasodilatation, cell cycle arrest, antiproliferation and apoptosis are mediated by AT2R, whereas action via AT1 causes vascular contraction, proliferation and cell growth (7). AngII affects the proliferation of prostate cancer cells (8) mainly due to the local tissue RAS, also depending on receptor type. Synthesis and function of AngII can be regulated by androgens in the prostate gland (2).

Another RAS component, angiotensin 1-7 (Ang1-7) is a product of AngII proteolysis (9). Ang1-7 can bind to the AT1 and AT2 receptor or to its specific G-protein coupled Mas receptor (10). The physiological effects of Ang1-7 are generally opposite to the effects of AngII (9), and it has been shown that Ang1-7 displays an antitumor effect in vivo and attenuates cytopenia. Thus, it has potential in chemotherapy, and does not cause hematologically toxic effects $(11,12)$.

In Western countries prostate cancer is one of the most common malignant diseases among men over 50 years of age (13). In vitro tests of potential treatments are frequently carried out using the hormone-independent human prostate cancer DU145 human cell line (14). Nevertheless, to date, hormonal therapy for prostate cancer is possible only in the case of androgen sensitivity of the tumor. Steroid hormones can evoke changes in cells by binding to their own or other receptors both intracellular and membrane. Thus, steroids can exhibit both genomic and non-genomic action. The biological 
activity of testosterone occurs mainly through binding with the intracellular specific androgen receptor affecting gene expression but data indicate the possibility of rapid, non-genomic action of testosterone, including prostate cancer cells $(15,16)$. These effects are considered to be non-genomic, because they appear within minutes, too rapidly to involve changes in gene transcription, and occur often in cells that lack a functional AR, similar to DU145 (17). Additionally, testosterone can be converted to its metabolite $17 \beta$-estradiol, which can be active in prostate cells and can act both in genomic and non-genomic manners, involving specific estradiol receptor or receptors of other factors including angiotensin family peptides (18).

In the present study, we examined the effects of testosterone and $17 \beta$-estradiol on angiotensin-induced changes in human metastatic prostate cancer DU-145 cells. This line is androgen receptor-negative, and does not respond to androgen hormones in a classical way. We focused on the potential non-genomic action of testosterone and $17 \beta$-estradiol, using short periods of exposure. We verified changes in the activity of PTKs, as they are important factors in cancer development and their activity is upregulated in tumors, such as prostate cancer (19). Furthermore, we elucidated the participation of AT1 and AT2 receptors in $17 \beta$-estradiol-induced or testosterone-induced changes in the angiotensin effect. We used losartan and PD123319, specific antagonists of AT1 and AT2, respectively.

\section{Materials and methods}

All chemicals used were of analytical grade. If not stated, chemicals were purchased from Sigma Aldrich (St. Louis, MO, USA).

Cell culture. The DU145 cell line was purchased from the American Type Culture Collection (ATCC; Manassas, VA, USA). The cell line was authenticated by short-tandem repeat (STR) DNA profiling. Cells were cultured in Dulbecco's modified Eagle's medium (DMEM; Sigma-Aldrich; Merck Millipore, Darmstadt, Germany) supplemented with $10 \%$ heat-inactivated fetal bovine serum (FBS; Biowest, Nuaille, France), $2 \mathrm{mM}$ L-glutamine, penicillin (50 U/ml), streptomycin $(50 \mu \mathrm{g} / \mathrm{ml})$ and neomycin $(100 \mu \mathrm{g} / \mathrm{ml})$ in a humidified atmosphere under $5 \% \mathrm{CO}_{2}$ at $37^{\circ} \mathrm{C}$.

Western blot analysis. Cells were incubated for $24 \mathrm{~h}$ with $5 \mathrm{nM}$ AngII or Ang1-7 with or without $1 \mathrm{~h}$ preincubation with $100 \mu \mathrm{M}$ $17 \beta$-estradiol or testosterone. Cells were then washed once in PBS and lysed in 60-100 $\mu 1$ of RIPA buffer supplemented with protease and phosphatase inhibitors for $30 \mathrm{~min}$ at $4^{\circ} \mathrm{C}$. Lysates were centrifuged at $14,000 \mathrm{rpm}$ for $20 \mathrm{~min}$ to remove insoluble material. Protein concentration was measured using Bradford Protein Assay kit (Bio-Rad, Berkeley, CA, USA). Lysates were incubated with Laemmli buffer at $95^{\circ} \mathrm{C}$ for $5 \mathrm{~min}$. Protein samples $(30 \mu \mathrm{g})$ were separated on a $10 \%$ polyacrylamide gel and transferred to nitrocellulose membranes using a Mini-PROTEAN Tetra system (Bio-Rad). Non-specific protein binding sites were blocked for $1 \mathrm{~h}$ at room temperature, using $5 \%$ BSA in TBST buffer. Nitrocellulose membranes were then incubated overnight at $4^{\circ} \mathrm{C}$ with anti-AT1, anti-AT2 and GAPDH primary antibodies (Santa Cruz Biotechnology, Inc., Santa Cruz, CA, USA) and in alkaline phosphatase-labelled secondary antibodies (Sigma) for $1 \mathrm{~h}$ at room temperature. The positive bands were revealed using Sigma-Fast BCIP/NBT reagent (Sigma-Aldrich). Blots were analyzed by densitometry using Quantity One software (Bio-Rad). The relative expression of AT1R or AT2R was determined by comparing their protein expression level to those of GADPH.

PTK activity. Cells were suspended in medium containing $32 \mathrm{mM}$ sacharose, $50 \mu \mathrm{M}$ EDTA, $10 \mathrm{mM}$ Tris/ $\mathrm{HCl} \mathrm{pH} 7.4$, $50 \mu \mathrm{M}$ PMSF and aprotinin $25 \mathrm{KIU} / \mathrm{ml}$ at $4^{\circ} \mathrm{C}$. Samples were pretreated with $10 \mu \mathrm{M}$ testosterone or $17 \beta$-estradiol for $15 \mathrm{~min}$ at $37^{\circ} \mathrm{C}$. After preincubation, AngII or Ang1-7 were added to both types of samples. Concentrations of angiotensins were $50 \mathrm{pM}, 500 \mathrm{pM}$ and $5 \mathrm{nM}\left(5 \times 10^{-11}\right.$ to $\left.5 \times 10^{-9} \mathrm{M}\right)$. Following $15 \mathrm{~min}$, the samples were lysed with $0.1 \%$ Triton $\mathrm{X}-100$ for $15 \mathrm{~min}$ at $0^{\circ} \mathrm{C}$. PTK activity was assessed according to the method of Hirano et al $(20,21)$ with modifications. $\gamma-\left[{ }^{32} \mathrm{P}\right]$-ATP (200 mM; DuPont NEN, Boston, MA, USA) and Poly(Glu, Tyr) (4:1) were used as substrates for phosphorylation by PTKs or phosphorylation reaction. Poly(Glu, Tyr)-free samples were taken as phosphorylation control. All samples were incubated for $7 \mathrm{~min}$ at $30^{\circ} \mathrm{C}$. Radioactivity of ${ }^{32} \mathrm{P}$ binding to the substrate was measured as Cerencov radiation using a liquid scintillation analyzer (Canberra-Packard, Bucharest, Romania). The activity of PTKs was defined as the amount in pmol of ${ }^{32} \mathrm{P}$ incorporated to Poly(Glu, Tyr) per $1 \mathrm{mg}$ of protein per $1 \mathrm{~min}$ ( $\mathrm{pmol} / \mathrm{mg} / \mathrm{min}$ ). Results were compared to the basal activity of PTKs (control) obtained from the samples containing only cyclodextrin which was a carrier of steroid hormones. The degree of ${ }^{32} \mathrm{P}$ incorporation to specific substrate by PTKs in the control group (basal activity) was taken as $100 \%$.

The inhibitors of angiotensin receptors, losartan (Adamed Group, Czosnów, Poland) or PD319131 were added to samples before tested hormones at the final concentrations during preincubation $10^{-8} \mathrm{M}(21)$

Statistical analysis. Data are expressed as mean \pm SEM of independent experiments from at least 3-4 cultures; from each culture we obtained 4-6 results. Statistical analysis was performed with the t-test, using Statistica 12 software. $\mathrm{P}<0.05$ was considered to indicate a statistically significant difference.

\section{Results}

We used cyclodextrin-conjugated $17 \beta$-estradiol and testosterone. Thus, in each experiment, the control culture medium contained cyclodextrin. Cyclodextrin alone does not affect any parameters which are subjects of the present study.

$17 \beta$-estradiol and testosterone modify the angiotensin-induced decrease in PTK activity. Cells were exposed to $50 \mathrm{pM}, 500 \mathrm{pM}$ and $5 \mathrm{nM}$ AngII or Ang1-7. These concentrations were chosen since they were previously confirmed to be most efficient in altering the activity of PTKs $(21,22)$. Here, administration of AngII alone decreased the activity of the PTKs (Fig. 1). We observed a slight positive correlation between the concentration of AngII and the strength of its inhibitory effect. Ang1-7 was effective only at higher concentrations (Fig. 2).

Steroids alone did not induce significant change in PTK activity (data not shown), but they acted to inverse the inhibitory 

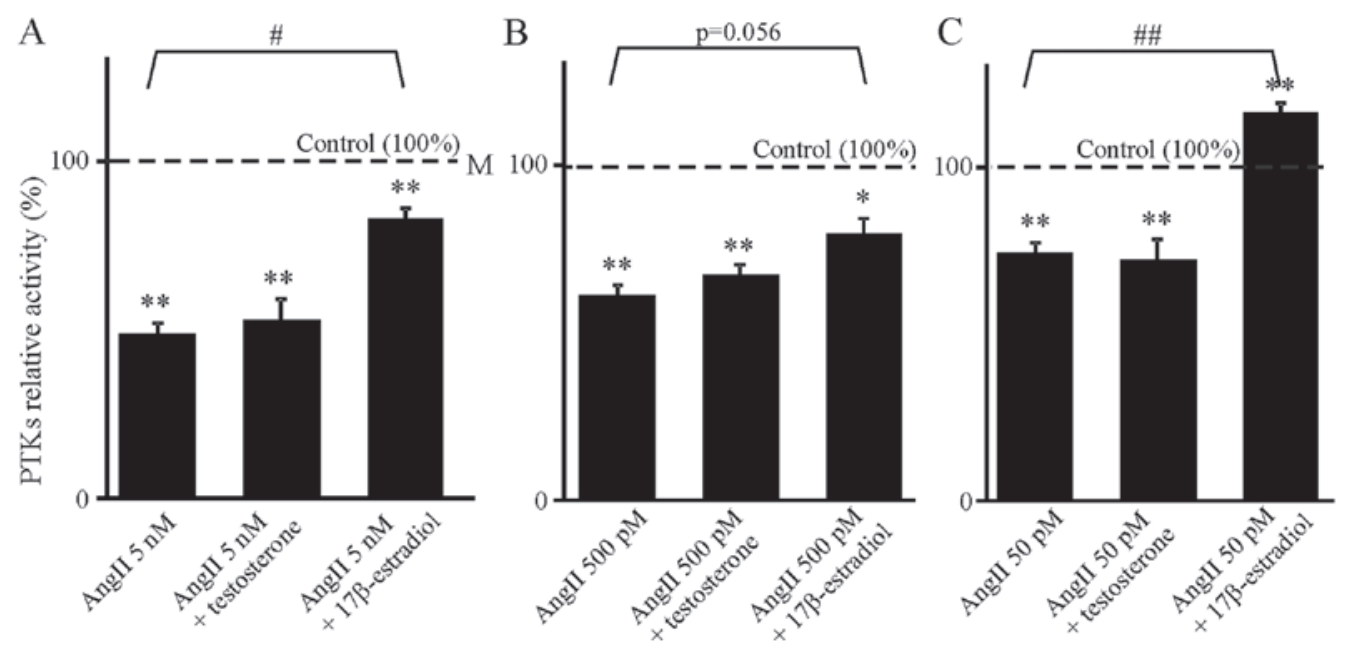

Figure 1. Effect of angiotensin II, testosterone and 17ß-estradiol on the activity of protein tyrosine kinases. Angiotensin II (AngII) concentrations: (A) $5 \mathrm{nM}$; (B) $500 \mathrm{pM}$ and (C) $50 \mathrm{pM}$. The activity of protein tyrosine kinases (PTKs) was defined as the amount in pmol of ${ }^{32} \mathrm{P}$ incorporated to substrate per $1 \mathrm{mg}$ of protein per $1 \mathrm{~min}$. The degree of ${ }^{32} \mathrm{P}$ incorporation to specific substrate by PTKs in cells treated with cyclodextrin alone (control) was assumed as $100 \%$ and other results were compared to this basal activity of PTKs in the control sample (relative activity of PTKs). Cyclodextrin alone had no effect on the PTK activity. Testosterone $(10 \mu \mathrm{M}) ; 17 \beta$-estradiol $(10 \mu \mathrm{M})$. Data are expressed as mean $\pm \mathrm{SEM} ;{ }^{*} \mathrm{p}<0.05 ;{ }^{\#} \mathrm{p}<0.05 ;{ }^{* * *} \mathrm{p}<0.01 ;{ }^{\# \#} \mathrm{p}<0.01 ; \mathrm{n}=18(4$ independent cultures, 4-6 results from each culture).
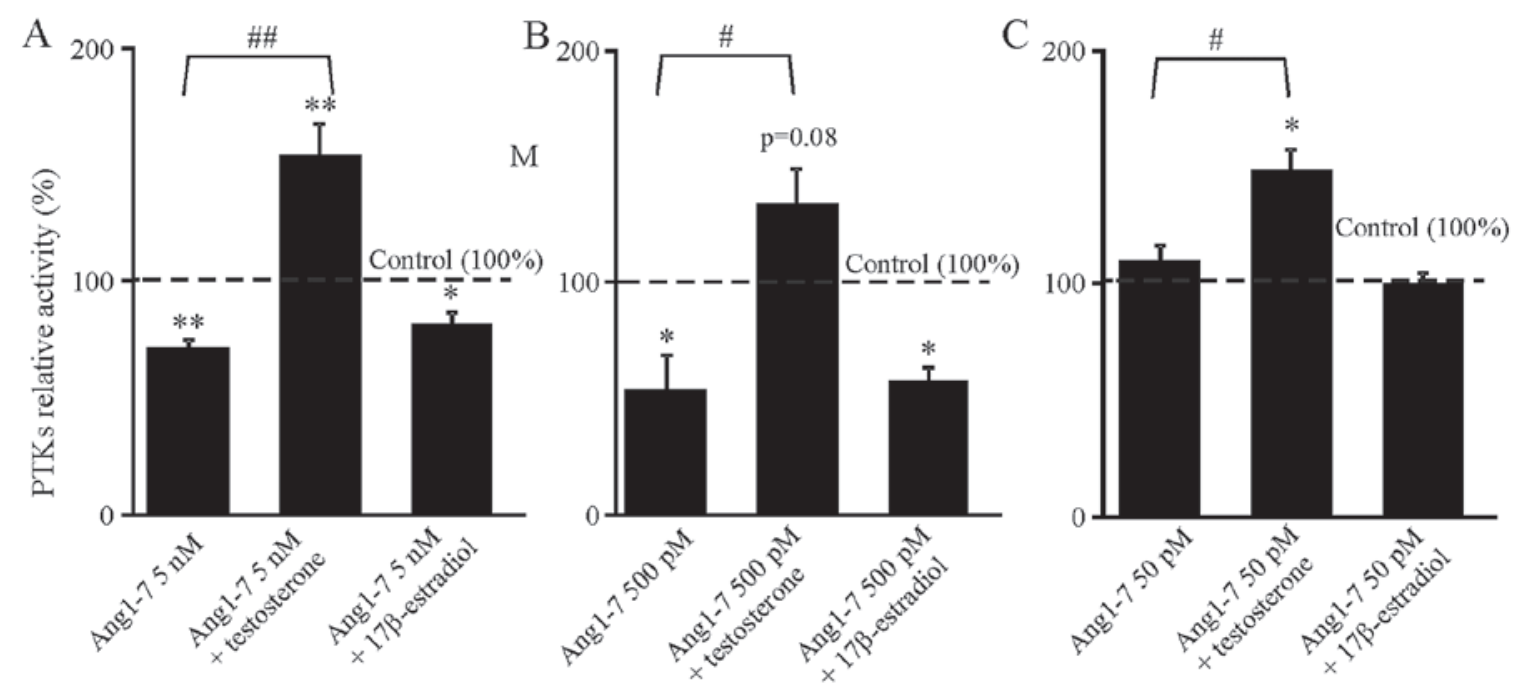

Figure 2. Effect of angiotensin 1-7, testosterone and 17 $\beta$-estradiol on the activity of protein tyrosine kinases. Angiotensin 1-7 (Ang 1-7) concentrations: (A) $5 \mathrm{nM}$; (B) $500 \mathrm{pM}$ and (C) $50 \mathrm{pM}$. The activity of protein tyrosine kinases (PTKs) was defined as the amount in pmol of ${ }^{32} \mathrm{P}$ incorporated to substrate per $1 \mathrm{mg}$ of protein per $1 \mathrm{~min}$. The degree of ${ }^{32} \mathrm{P}$ incorporation to specific substrate by PTKs in cells treated with cyclodextrin alone (control) was assumed as $100 \%$ and other results were compared to basal activity of PTKs in the control sample (relative activity of PTKs). Cyclodextrin alone had no effect on the PTK activity. Testosterone $(10 \mu \mathrm{M}) ; 17 \beta$-estradiol $(10 \mu \mathrm{M})$. Data are expressed as mean $\pm \mathrm{SEM} ;{ }^{*} \mathrm{p}<0.05 ;{ }^{*} \mathrm{p}<0.05 ;{ }^{* *} \mathrm{p}<0.01 ;{ }^{\# \#} \mathrm{p}<0.01 ; \mathrm{n}=18(4 \mathrm{independent}$ cultures, 4-6 results from each culture).

effect of angiotensin. Moreover, testosterone and 17 $\beta$-estradiol $(10 \mu \mathrm{M})$ showed clearly specific interaction; estradiol reversed inhibition caused only by AngII (Fig. 1), and testosterone reversed inhibition caused only by Ang1-7 (Fig. 2). In each case this effect was statistically significant or close to achieving statistical significance (Fig. 1B). Furthermore, combination of 50 pM AngII with 17 $\beta$-estradiol increased PTK activity above the control value (Fig. 1C). The same applied to the combination of Ang1-7 and testosterone (Fig. 2A-C).

Effect of steroid hormones on AngII-induced enhancement of AT1R and AT2R expression. AngII induced expression of
AT1R, but we observed an additional significant increase in the AT2R level in the presence of AngII (Fig. 3). This effect was not affected by the hormones. Ang1-7 increased the expression of AT1R and this effect was attenuated by $17 \beta$-estradiol, but not by testosterone (Fig. 3C). Expression of AT2R was affected neither by Ang1-7 alone, nor by Ang1-7 together with 17 $\beta$-estradiol or testosterone (Fig. 3).

Involvement of AT1R and AT2R in the effect of steroids on angiotensin-induced PTK inhibition. In order to determine the involvement of AT1 and AT2 receptors in the steroids we used selective blockers of both receptors. The results 

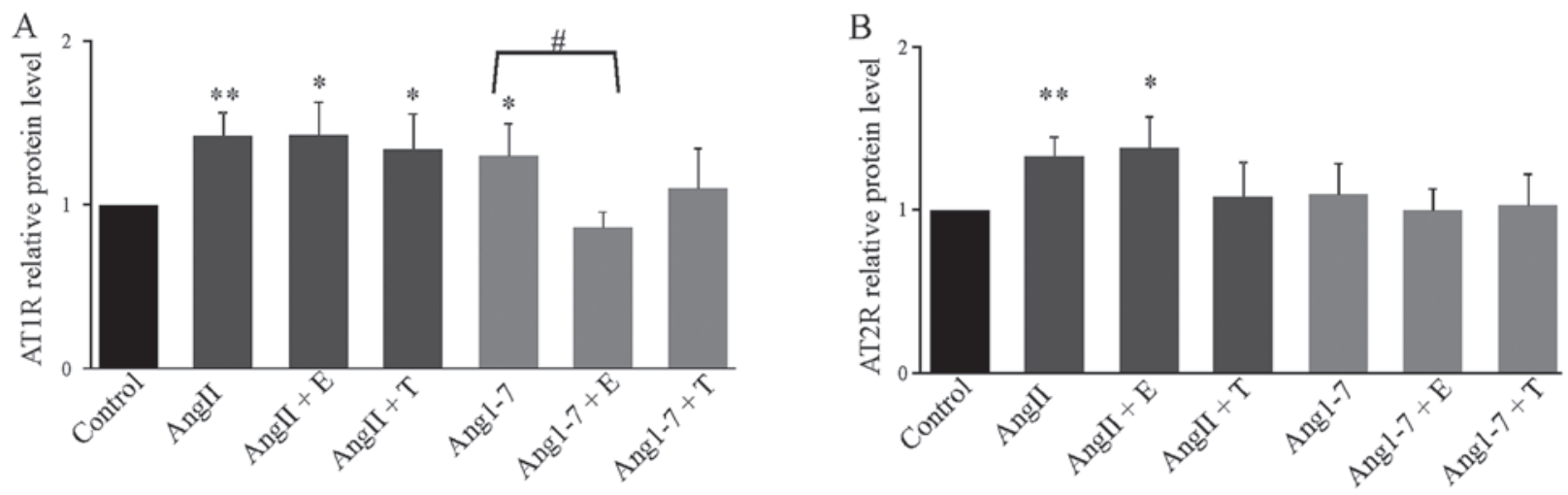

$\mathrm{C}$

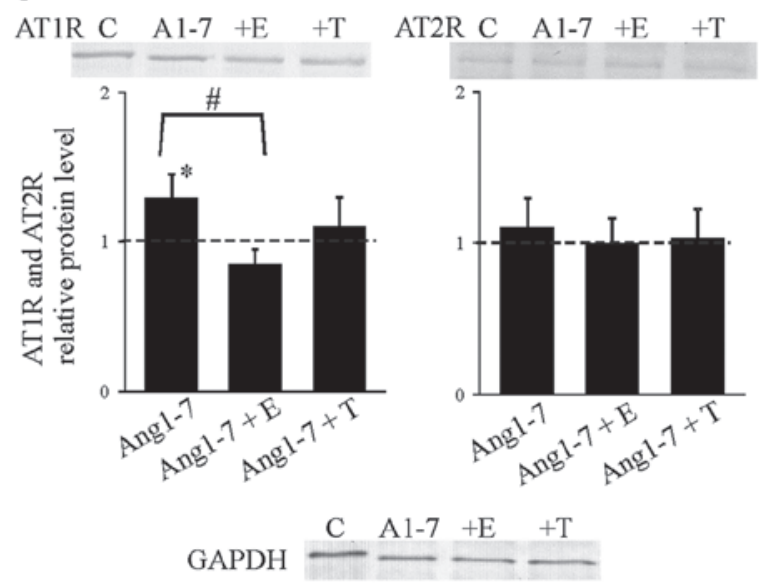

Figure 3. (A-C) Effect of $5 \mathrm{nM}$ Ang 1-7, $5 \mathrm{nM}$ AngII, $100 \mu \mathrm{M} 17 \beta$-estradiol and $100 \mu \mathrm{M}$ testosterone on the expression of AT1 and AT2 receptors by western blotting. (A) Changes in AT1R protein level caused by angiotensin II (AngII), angiotensin 1-7 (Ang 1-7) and hormones. (B) Changes in AT2R protein level caused by AngII, Ang 1-7 and hormones. (C) Comparison of the effect of steroids on Ang 1-7-evoked changes in receptor expression. Results were normalized to GAPDH. The protein receptor level in cells treated with cyclodextrin alone was assumed as the control (arbitrary unit=1) (relative AT1R or AT2R protein level-arbitrary unit). Cyclodextrin alone had no effect. C, control; A1-7, Ang1-7; T, testosterone; E, 17 $\beta$-estradiol. Data are expressed as mean \pm SEM of three different experiments; ${ }^{*}, * \mathrm{p}<0.05$.
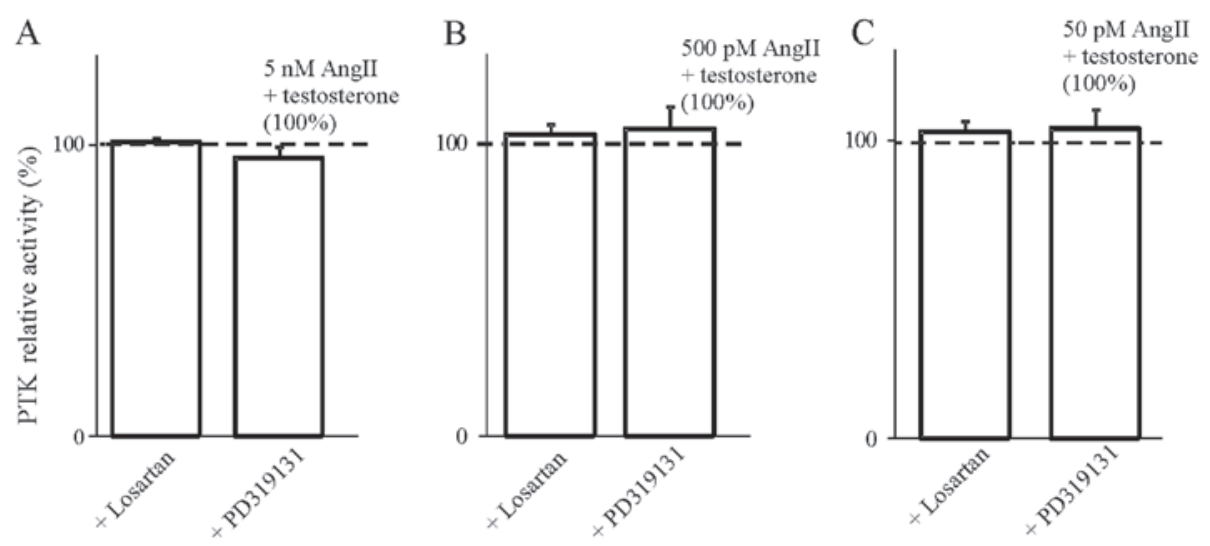

Figure 4. Participation of AT1 and AT2 receptors in AngII and testosterone-dependent modulation of protein tyrosine kinase activity. Losartan (10-8 $\mathrm{M})$ and PD123319 (PD; $10^{-8} \mathrm{M}$ ) were used as inhibitors of AT1R and AT2R, respectively. The degree of ${ }^{32} \mathrm{P}$ incorporation to specific substrate by protein tyrosine kinases (PTKs) in cells exposed to angiotensin II (AngII) and testosterone $(10 \mu \mathrm{M})$ were assumed as control (100\%). AngII concentrations: (A) $5 \mathrm{nM}$; (B) $500 \mathrm{pM}$ and (C) $50 \mathrm{pM}$. Data are expressed as mean \pm SEM; $\mathrm{n}=18$ (4 independent cultures, 4-6 results from each culture).

presented in Figs. 4-7 indicate that the use of the selective inhibitor of AT2, PD319131 $\left(10^{-8} \mathrm{M}\right)$ caused the inhibition of the simultaneous effect of Ang1-7 and testosterone at all tested concentrations of angiotensin peptide. This suggests that testosterone influences the interaction of Ang1-7 with the AT2 receptor. The lack of an inhibitory effect of receptor blockers on the action of AngII in the presence of $17 \beta$-estradiol suggest that the weak action of $17 \beta$-estradiol on AngII-induced inhibition of PTK activity was caused by mechanisms independent of the AT1 and AT2 receptors. 


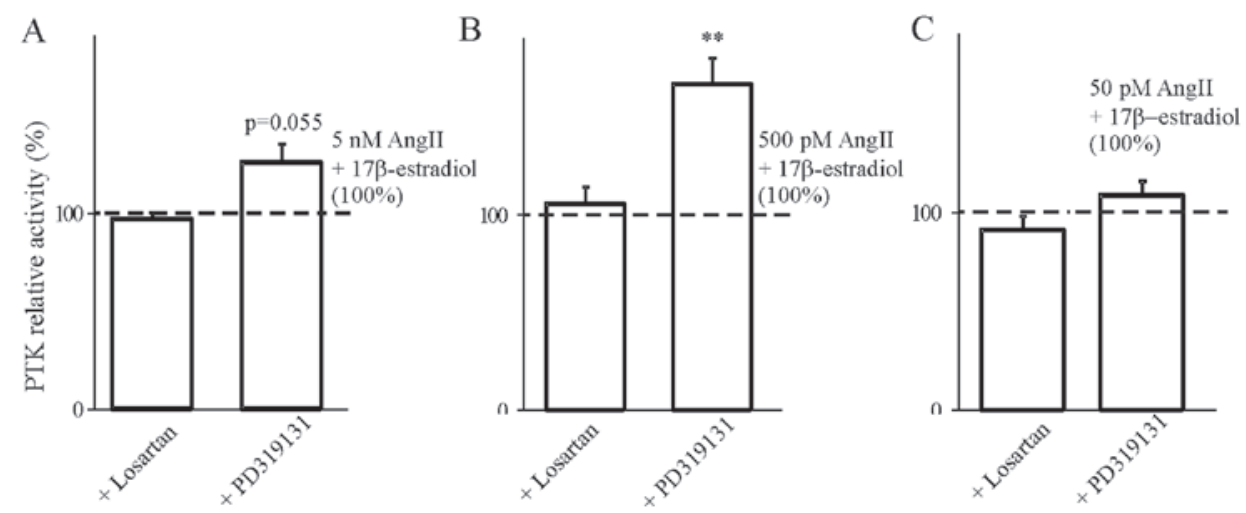

Figure 5. Participation of AT1 and AT2 receptors in AngII and 17ß-estradiol-dependent modulation of protein tyrosine kinase activity. Losartan (10 $\left.{ }^{-8} \mathrm{M}\right)$ and PD123319 $\left(\mathrm{PD} ; 10^{-8} \mathrm{M}\right)$ were used as inhibitors of AT1R and AT2R, respectively. The degree of ${ }^{32} \mathrm{P}$ incorporation to specific substrate by protein tyrosine kinases (PTKs) in cells exposed to angiotensin II (AngII) and 17ß-estradiol $(10 \mu \mathrm{M})$ were assumed as control (100\%). AngII concentrations: (A) $5 \mathrm{nM}$; (B) $500 \mathrm{pM}$; (C) $50 \mathrm{pM}$. Data are expressed as mean $\pm \mathrm{SEM}$; ${ }^{\mathrm{p}} \mathrm{p}<0.05 ; \mathrm{n}=18$ (4 independent cultures, 4-6 results from each culture).
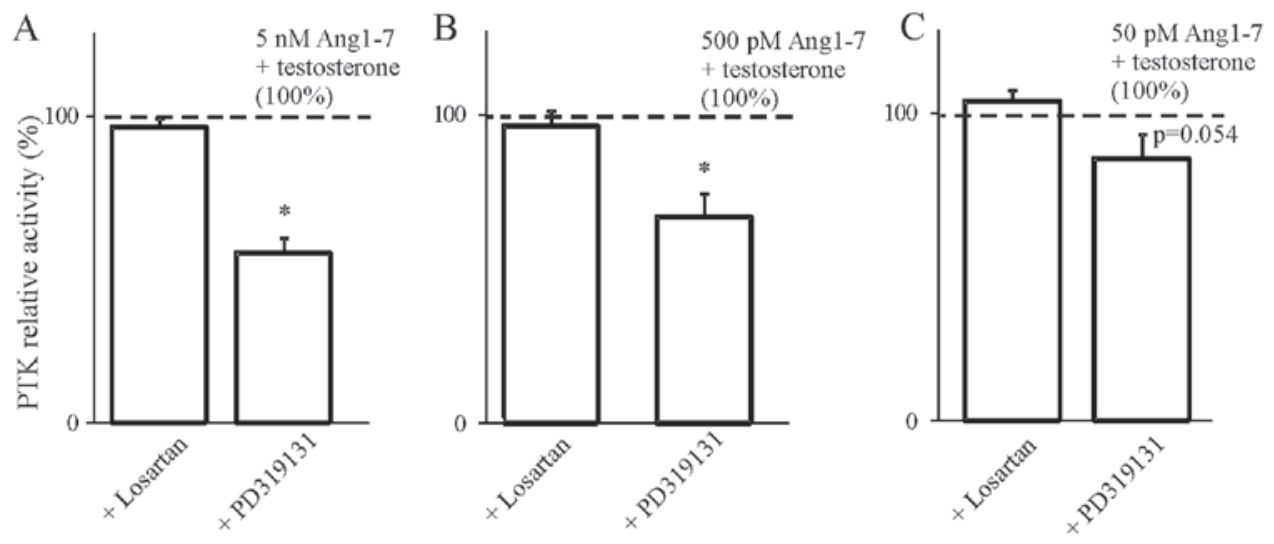

Figure 6. Participation of AT1 and AT2 receptors in Ang1-7 and testosterone-dependent modulation of protein tyrosine kinase activity. Losartan (10-8 M) and PD123319 (PD; $10^{-8} \mathrm{M}$ ) were used as inhibitors of AT1R and AT2R, respectively. The degree of ${ }^{32} \mathrm{P}$ incorporation to specific substrate by protein tyrosine kinases (PTKs) in cells exposed to angiotensin 1-7 (Ang 1-7) and testosterone (10 $\mu \mathrm{M})$ were assumed as control (100\%). Ang1-7 concentrations: (A) $5 \mathrm{nM}$; (B) $500 \mathrm{pM}$; (C) $50 \mathrm{pM}$. Data expressed as mean $\pm \mathrm{SEM}$; "p $<0.05 \mathrm{n}=18$ (4 independent cultures, 4-6 results from each culture). Ang1-7, angiotensin 1-7.
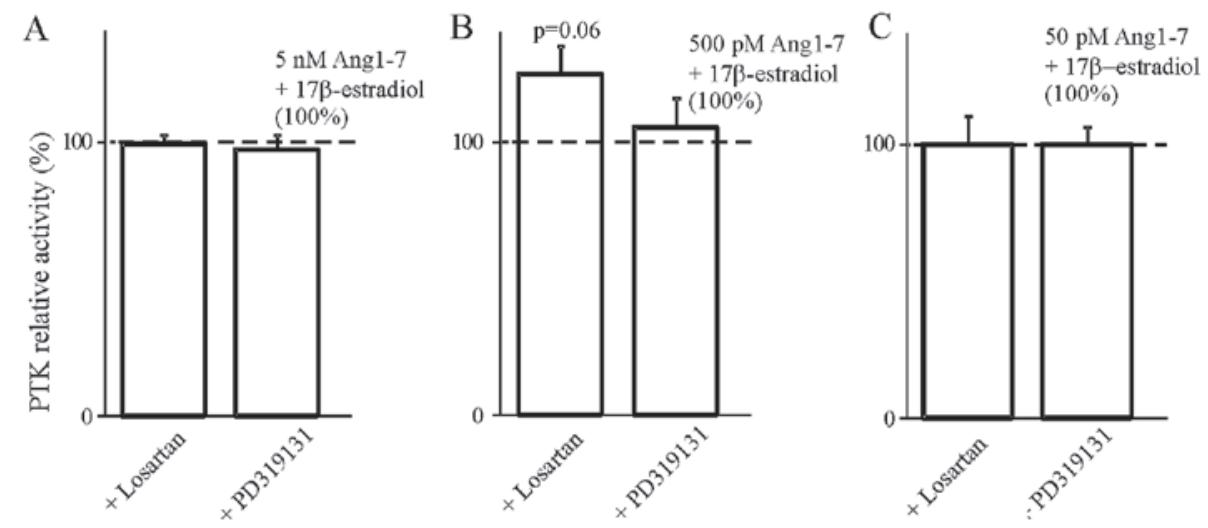

Figure 7. Participation of AT1 and AT2 receptors in Ang1-7 and 17ß-estradiol-dependent modulation of protein tyrosine kinases activity. Losartan (10-8 $\mathrm{M})$ and PD123319 (PD) $\left(10^{-8} \mathrm{M}\right)$ were used as inhibitors of AT1R and AT2R, respectively. The degree of ${ }^{32} \mathrm{P}$ incorporation to specific substrate by protein tyrosine kinases (PTKs) in cells exposed to angiotensin 1-7 (Ang 1-7) and 17ß-estradiol (10 $\mu \mathrm{M})$ were assumed as control (100\%). Ang1-7 concentrations: (A) $5 \mathrm{nM}$; (B) $500 \mathrm{pM}$ and (C) $50 \mathrm{pM}$. Data expressed as mean \pm SEM; $\mathrm{n}=18$ (4 independent cultures, 4-6 results from each culture).

\section{Discussion}

Prostate cancer is one of the most common diseases and its mortality rate is increasing. The patient survival rate is reduced in cases of late diagnosis when cells acquire metastatic ability and become resistant to hormone treatment. One of the best models in prostate cancer studies is the DU145 cell line, characterized by lack or very low expression of the 
A

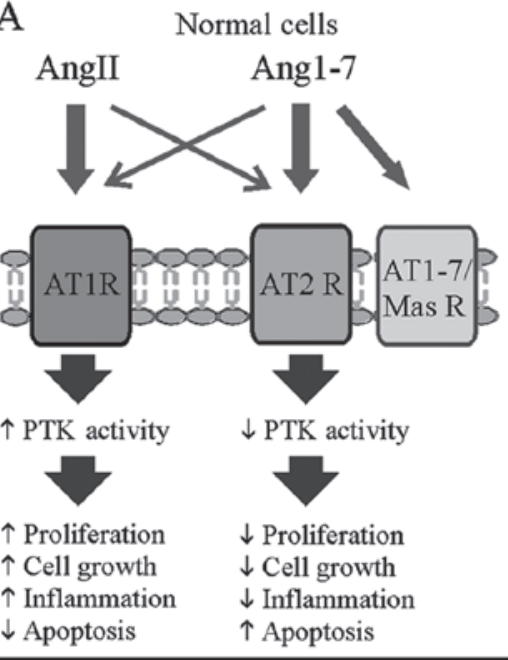

B

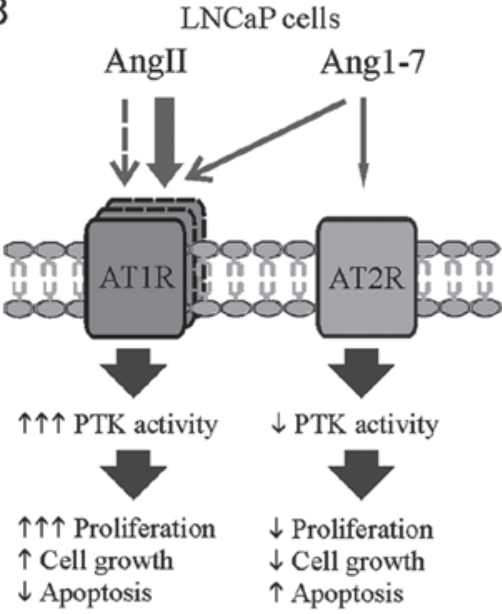

$\mathrm{C}$

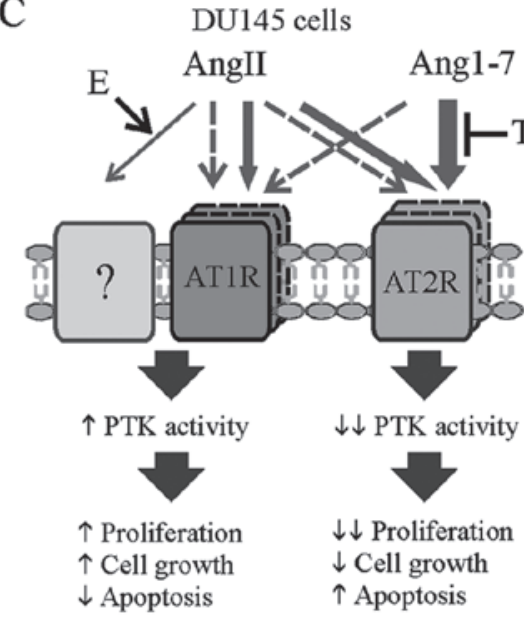

Fast conversion to late,

metastatic, more

aggressive stage
Induction of protective mechanisms, inhibition of cancer development

Figure 8. The possible action of angiotensin II (AngII) and angiotensin 1-7 (Ang1-7) in (A) normal cells, (B) LNCaP and (C) DU145 cell lines. (A and B) Based on the literature data $(42,59)$. (C) Suggested action based on the obtained results. (A) In normal cells the effects caused by the binding of AngII and Ang1-7 with AT1R and AT2R are in balance. (B) In LNCaP cells strong activation of AT1R by AngII and increased expression of this receptor lead to enhanced stimulation of protein tyrosine kinases (PTKs) which finally causes increased cancer cell proliferation and fast conversion to late, metastatic, more aggressive stage. (C) In DU145 cells activation of AT2R by Ang1-7 can lead to inhibition of PTK activity and reduction in cell proliferation. It can provoke induction of protective mechanisms and reduction in the rate of cancer development. Solid line, interaction of angiotensins with AT1 or AT2 receptors; Dashed line, effect of angiotensins on receptor expression (increased number of receptor). Thickness of arrows reflects potency of AngII or Ang1-7 interaction with receptors. E, 17ß-estradiol; T, testosterone.

androgen receptor (23). There are several differences between androgen-insensitive cell lines and androgen-responsive cells e.g., LNCaP, which are more susceptible to hormonal treatment. However, the classical receptor-mediated effect is not the only one possible of testosterone action. The rapid membrane effect of testosterone mediated through unconventional membrane androgen receptors was documented in LNCaP and DU145 cells (24). Equally important is the fact that this can be also mediated by testosterone metabolite-17 $\beta$-estradiol. Androgen-independent DU145 cells express both classical estradiol receptors, ER $\alpha$ and ER $\beta$ (25), and show high activity of $5 \alpha$-reductase and aromatase (26). ER $\alpha$ is expressed in prostatic tissue mainly during fetal and early neonatal life. Invalid activation of ER $\alpha$ causes late-life diseases, including inflammation and pre-malignant pathologies. In contrast, ER $\beta$ expression appears later, after $\mathrm{ER} \alpha$, primarily in the epithelium. It seems to be an important factor of regulation of cell proliferation and regulation of differentiation in adult tissue and during puberty (25). This isoform predominates in late, metastatic cells of prostate cancer such as DU145 cells (27). It is known that although the androgen level decreases with age, the level of estrogens in males remains unchanged and even increases. Androgens (including testosterone) are necessary for normal prostate development and function, while in many cases estradiol speeds up the development of prostate cancer (28). Yet, it appears that both synthetic and natural (including exogenous) modulators of ER $\beta$ show protective properties against cancer progression by inhibition of cell proliferation and migration, and can be utilized in the therapy of prostate cancer including androgen-independent cancer $(27,29)$ Therefore, it is important to determine the function of both steroids in DU145 cells.
There is evidence of a relationship between androgen and RAS. In prostate cells this relationship is additively complicated by the fact that angiotensins can interact with steroid receptors and contrariwise steroids may bind to angiotensin receptors. Other studies have shown that signaling transmission by G-protein coupled receptors (including angiotensin receptors) can induced androgen-independent androgen receptor activation causing the conversion of androgen-dependent cells to androgen-independent cells (30). On the other hand some studies indicate that estrogens affect components of RAS, e.g., decrease the expression of AT1R and increase AT2R expression $(31,32)$. Testosterone directly leads to upregulation of RAS components including AT2 receptor expression (32). The overlapping effects of angiotensins and steroids can be detrimental to the cell and can be the cause of cancer treatment failure.

Local RAS plays an important role in cancer development $(33,34)$. Elements of RAS exist in both normal and cancer cells including cell lines $(34,35)$. Local RAS includes angiotensin-family peptides, enzymes involved in their synthesis and metabolism, and angiotensin receptors. RAS is implicated in the development of various cancers, and changes in the expression of RAS components in most cases are correlated with cancer grade, however they are not consistent and depend on tumor type and degree of cancer possibly due to various cellular pathways initiated by RAS (35). Elements of intracellular signaling pathways, which are activated by angiotensins, such as tyrosine kinases, can be also classified to RAS (5). RAS and tyrosine kinases are now targets in cancer therapies, including prostate cancer (35-37).

Recent studies show that angiotensins may modulate the proliferation and migration of cells, which promotes cancer 
development and metastasis. Angiotensins can influence prostate cancer cells (PC3, DU145 and LNCaP) in different ways, depending on the type of cell $(21,38,39)$. Data indicate the importance of the angiotensin peptide type and time of exposure for progression of prostate cancer. In addition, the action of angiotensin family peptides in cancer cells is intricate and depends on cancer type and development stage.

In most cases, in cancer cells the activity of tyrosine kinases is much higher than that in healthy cells (40). PTKs play important roles in adverse, very fast proliferation of cells. But in some types of cells, including cancer, tyrosine kinases can mediate apoptosis or differentiation (41). Previous studies indicate that angiotensin peptides modulate the tyrosine kinase activity in pituitary $(22,42), \mathrm{MCF}$ and MDA cell lines (43) in a concentration-dependent manner. Notable is the similarity of the inhibitory effect of AngII on PTK activity in hormone-sensitive cell lines (LNCaP and MCF-7). In hormone-independent lines (DU145 and MDA-MB-231) angiotensin had a stronger inhibitory effect (43).

We found that both AngII and Ang1-7 decreased tyrosine kinase activity. We rather expected that the action of both peptides would be opposite and that AngII would stimulate PTKs while Ang1-7 would decrease their activity. The DU145 cell line is more advanced in terms of the development of cancer and may show distinct properties and processes responsible for cancer development in this line may be upset. Inhibition of tyrosine kinases seems to be positive (protective) because of possible simultaneous inhibition of proliferation. This unexpected inhibition of PTK activity may be explained by the interaction of AngII with the AT2 receptor as the mechanism of angiotensin action depends on the type of receptor. Activation of AT1R causes the pro-inflammatory and pro-cancerogenic action of ligands, while stimulation of AT2R leads to pro-apoptotic and anti-proliferative effects of angiotensins.

Opposite physiological effects caused by both peptides are considered to be associated with different affinity of the two types of receptors to AngII and Ang1-7. T1R can bind both AngII and Ang1-7, but has higher affinity to AngII in normal cells. AT2R can also bind both peptides, but in normal cells, it preferably binds Ang1-7. Aditionally, Ang1-7 can bind to a third receptor, specific to Ang1-7 only (AT1-7/Mas receptor), which is also found in testis (44). Commonly, AngII preferably binds to AT1R causing unfavorable effects, while antagonists of AT1R show strong antiproliferative activity and inhibit angiogenesis in prostate cancer cells (45). Ang1-7 has higher affinity to AT2R, thus Ang1-7 can significantly decrease the size of tumors as well as activity of kinases which participate in proliferation (11).

As mentioned earlier, expression of AT1R and AT2R was found in prostate cancer cells $(46,47)$ while expression of both types of receptors can differ in LNCaP and DU145 cells (47). In androgen-positive LNCap cells AT1R expression is higher than in late stage, androgen-independent DU154 cells and in healthy cells (34). This may be due to increased protein kinase activity, subsequent proliferation and finally the rapid conversion to metastatic, aggressive form of prostate cancer. Expression of angiotensin receptors at this late stage of prostate depends on the state of severity as well. Research has shown that in androgen-nonsensitive cells expression of AT2R is lower than AT1R and lower than that in androgen-positive cells (46). Our results indicate that in DU145 cells expression of AT2R was increased in the presence of AngII. Hence we suggest increased binding of AngII to AT2 receptor that results in the subsequent decrease in PTK activity.

It is well established that G-protein coupled receptors and tyrosine kinases can crosstalk and modulate each other (48). We observed an increase in PTK activity in the presence of Ang1-7 and testosterone or AngII and 17 $\beta$-estradiol. This may suggest that both steroids have procancerogenic features and can contribute to cancer progression. This is consistent with the fact that $17 \beta$-estradiol facilitates prostate cancer growth.

It is widely known that the pharmacological effects of steroids are linked with changes in gene transcription, but there is also increasing data concerning their rapid non-genomic actions. In the present study, we did not observe a significant effect of testosterone or $17 \beta$-estradiol on AT1R and AT2R expression in the presence of AngII or Ang1-7. Lack of a testosterone effect is not surprising and can be explained by absence or low expression of the androgen receptor, that eliminates a classical genomic mode of action. Yet, the results indicate that testosterone does not modify the stimulatory effect of angiotensins on receptor expression in any other way. The inhibitory impact of $17 \beta$-estradiol on AT1R expression in the presence of Ang 1-7 was possible thanks to the existence of estrogen receptors in the DU145 cells. But it seems, that changes in angiotensin-induced inhibition of tyrosine kinases are caused by direct interaction of hormones with existing angiotensin receptors rather, not by changes in receptor number. Additionally, the appearance of the effect after a quite short time, precluding genomic action enforces this hypothesis. Transcription alteration usually takes hours, but the effects of those described as non-genomic direct pathways can be noticed in a few minutes.

Withdrawal of changes triggered by testosterone after using specific AT2R blockers (PD19234) indicates the wider involvement of the AT2 receptor in this hormone action on Ang1-7-induced changes. Probably, in the cell line lacking androgen receptor, testosterone acts through AT2R characterized by a higher affinity to Ang1-7. The observed rise in PTK activity in the presence of AngII and 17 $\beta$-estradiol after inhibition of AT2R by a specific blocker probably was evoked by rapid interaction of both $17 \beta$-estradiol and AngII with other than angiotensin receptors, e.g., membrane receptors of estradiol. All the more so, AT1R, although found both in LNCaP and DU145, is only functional in LNCaP. In PC3 cells which are similar to DU145, AT1R seems to be non-functional (49).

In conclusion, both our and cited results indicate that local action of AngII and Ang1-7 on processes involved in cancer progression depend on: the type of peptide, peptide concentration, tissue, time of exposure and stage of cancer. In late stage prostate cancer cell lines (DU145) an observed decrease in protein kinase activity caused by both AngII and Ang1-7 may protect against further development of cancer. This suggests that treatment of RAS inhibitors for prostate cancer patients should be prudent. Steroid hormones, testosterone and $17 \beta$-estradiol reverse the action of angiotensins leading to adverse progression in prostate cancer (Fig. 8).

Due to the high specificity of the described interactions, further studies concerning the mechanism of action are warranted and may be useful to explain advanced stage cancer 
therapy failure. Further research is also warranted for the development of new cancer therapies.

\section{Acknowledgements}

The present study was supported by the Medical University of Lodz (Lodz, Poland; grant nos. 503/6-086-02/503-61-001; 502-03/0-078-04/502-04-030 and 502-03/6-086-02/ 502-64-109).

\section{References}

1. Uemura H, Hoshino K and Kubota Y: Engagement of renin-angiotensin system in prostate cancer. Curr Cancer Drug Targets 11: 442-450, 2011.

2. O'Mahony OA, Barker S, Puddefoot JR and Vinson GP: Synthesis and secretion of angiotensin II by the prostate gland in vitro. Endocrinology 146: 392-398, 2005.

3. Fujita M, Hayashi I, Yamashina S, Itoman M and Majima $\mathbf{M}$ : Blockade of angiotensin AT1a receptor signaling reduces tumor growth, angiogenesis, and metastasis. Biochem Biophys Res Commun 294: 441-447, 2002.

4. Namsolleck P, Recarti C, Foulquier S, Steckelings UM and Unger T: AT(2) receptor and tissue injury: Therapeutic implications. Curr Hypertens Rep 16: 416, 2014.

5. Haendeler J and Berk BC: Angiotensin II mediated signal transduction. Important role of tyrosine kinases. Regul Pept 95: 1-7, 2000.

6. McCarty MF: Targeting multiple signaling pathways as a strategy for managing prostate cancer: Multifocal signal modulation therapy. Integr Cancer Ther 3: 349-380, 2004.

7. Rodrigues-Ferreira S and Nahmias C: G-protein coupled receptors of the renin-angiotensin system: New targets against breast cancer? Front Pharmacol 6: 24, 2015.

8. Uemura H, Hasumi H, Ishiguro H, Teranishi J, Miyoshi Y and Kubota Y: Renin-angiotensin system is an important factor in hormone refractory prostate cancer. Prostate 66: 822-830, 2006.

9. Moon JY: Recent update of renin-angiotensin-aldosterone system in the pathogenesis of hypertension. Electrolyte Blood Press 11: 41-45, 2013.

10. Santos RA, Ferreira AJ, Verano-Braga $\mathrm{T}$ and Bader $\mathrm{M}$ : Angiotensin-converting enzyme 2, angiotensin-(1-7) and Mas: New players of the renin-angiotensin system. J Endocrinol 216 : R1-R17, 2013.

11. Krishnan B, Torti FM, Gallagher PE and Tallant EA: Angiotensin-(1-7) reduces proliferation and angiogenesis of human prostate cancer xenografts with a decrease in angiogenic factors and an increase in sFlt-1. Prostate 73: 60-70, 2013.

12. Krishnan B, Smith TL, Dubey P, Zapadka ME, Torti FM, Willingham MC, Tallant EA and Gallagher PE: Angiotensin-(1-7) attenuates metastatic prostate cancer and reduces osteoclastogenesis. Prostate 73: 71-82, 2013.

13. Hsing AW, Tsao L and Devesa SS: International trends and patterns of prostate cancer incidence and mortality. Int J Cancer 85: 60-67, 2000.

14. Stone KR, Mickey DD, Wunderli H, Mickey GH and Paulson DF: Isolation of a human prostate carcinoma cell line (DU 145). Int J Cancer 21: 274-281, 1978.

15. Sun YH, Gao X, Tang YJ, Xu CL and Wang LH: Androgens induce increases in intracellular calcium via a $\mathrm{G}$ protein-coupled receptor in LNCaP prostate cancer cells. J Androl 27: 671-678, 2006.

16. Falkenstein E, Tillmann HC, Christ $M$, Feuring $M$ and Wehling M: Multiple actions of steroid hormones - a focus on rapid, nongenomic effects. Pharmacol Rev 52: 513-556, 2000.

17. Guo Z, Benten WP, Krücken J and Wunderlich F: Nongenomic testosterone calcium signaling. Genotropic actions in androgen receptor-free macrophages. J Biol Chem 277: 29600-29607, 2002.

18. Yeh CR, Da J, Song W, Fazili A and Yeh S: Estrogen receptors in prostate development and cancer. Am J Clin Exp Urol 2: 161-168, 2014.

19. Vlahovic G and Crawford J: Activation of tyrosine kinases in cancer. Oncologist 8: 531-538, 2003.

20. Hirano AA, Greengard P and Huganir RL: Protein tyrosine kinase activity and its endogenous substrates in rat brain: A subcellular and regional survey. J Neurochem 50: 1447-1455, 1988.
21. Domińska K, Piastowska-Ciesielska AW, Lachowicz-Ochędalska A and Ochędalski T: Similarities and differences between effects of angiotensin III and angiotensin II on human prostate cancer cell migration and proliferation. Peptides 37: 200-206, 2012.

22. Rebas E, Zabczyńska J and Lachowicz A: The effect of angiotensin 1-7 on tyrosine kinases activity in rat anterior pituitary. Biochem Biophys Res Commun 347: 581-585, 2006.

23. Alimirah F, Chen J, Basrawala Z, Xin H and Choubey D: DU-145 and PC-3 human prostate cancer cell lines express androgen receptor: Implications for the androgen receptor functions and regulation. FEBS Lett 580: 2294-2300, 2006.

24. Wang Z, Liu L, Hou J, Wen D, Yan C, Pu J, Ouyang J and Pan H: Rapid membrane effect of testosterone in LNCaP cells. Urol Int 81: 353-359, 2008.

25. McPherson SJ, Ellem SJ and Risbridger GP: Estrogen-regulated development and differentiation of the prostate. Differentiation 76: 660-670, 2008

26. Negri-Cesi P, Colciago A, Poletti A and Motta M: $5 \alpha$-reductase isozymes and aromatase are differentially expressed and active in the androgen-independent human prostate cancer cell lines DU145 and PC3. Prostate 41: 224-232, 1999.

27. Piccolella M, Crippa V, Messi E, Tetel MJ and Poletti A: Modulators of estrogen receptor inhibit proliferation and migration of prostate cancer cells. Pharmacol Res 79: 13-20, 2014

28. Bonkhoff $\mathrm{H}$ and Berges R: The evolving role of oestrogens and their receptors in the development and progression of prostate cancer. Eur Urol 55: 533-542, 2009.

29. Ho SM: Estrogens and anti-estrogens: Key mediators of prostate carcinogenesis and new therapeutic candidates. J Cell Biochem 91: 491-503, 2004

30. Hoshino K, Ishiguro H, Teranishi J, Yoshida S, Umemura S, Kubota $\mathrm{Y}$ and Uemura $\mathrm{H}$ : Regulation of androgen receptor expression through angiotensin II type 1 receptor in prostate cancer cells. Prostate 71: 964-975, 2011.

31. Baiardi G, Macova M, Armando I, Ando H, Tyurmin D and Saavedra JM: Estrogen upregulates renal angiotensin II AT1 and AT2 receptors in the rat. Regul Pept 124: 7-17, 2005.

32. Hilliard LM, Sampson AK, Brown RD and Denton KM: The 'his and hers' of the renin-angiotensin system. Curr Hypertens Rep 15: 71-79, 2013.

33. Marchiani S, Tamburrino L, Nesi G, Paglierani M, Gelmini S, Orlando C, Maggi M, Forti G and Baldi E: Androgen-responsive and -unresponsive prostate cancer cell lines respond differently to stimuli inducing neuroendocrine differentiation. Int J Androl 33: 784-793, 2010.

34. Uemura H, Ishiguro H, Nakaigawa N, Nagashima Y, Miyoshi Y, Fujinami K, Sakaguchi A and Kubota Y: Angiotensin II receptor blocker shows antiproliferative activity in prostate cancer cells: A possibility of tyrosine kinase inhibitor of growth factor. Mol Cancer Ther 2: 1139-1147, 2003.

35. Ager EI, Neo J and Christophi C: The renin-angiotensin system and malignancy. Carcinogenesis 29: 1675-1684, 2008.

36. Ullén A, Farnebo M, Thyrell L, Mahmoudi S, Kharaziha P, Lennartsson L, Grandér D, Panaretakis T and Nilsson S: Sorafenib induces apoptosis and autophagy in prostate cancer cells in vitro. Int J Oncol 37: 15-20, 2010.

37. Brooks C, Sheu T, Bridges K, Mason K, Kuban D, Mathew P and Meyn R: Preclinical evaluation of sunitinib, a multi-tyrosine kinase inhibitor, as a radiosensitizer for human prostate cancer. Radiat Oncol 7: 154-163, 2012.

38. Ławnicka H, Potocka AM, Juzala A, Fournie-Zaluski MC and Pawlikowski M: Angiotensin II and its fragments (angiotensins III and IV) decrease the growth of DU-145 prostate cancer in vitro. Med Sci Monit 10: BR410-BR413, 2004

39. Domińska K, Piastowska-Ciesielska AW, Płuciennik E, Lachowicz-Ochędalska A and Ochedalski T: A comparison of the effects of Angiotensin IV on androgen-dependent and androgen-independent prostate cancer cell lines. J Renin Angiotensin Aldosterone Syst 14: 74-81, 2013.

40. Brand TM, Iida M, Li C and Wheeler DL: The nuclear epidermal growth factor receptor signaling network and its role in cancer. Discov Med 12: 419-432, 2011.

41. Montero JC, Seoane S, Ocaña A and Pandiella A: Inhibition of SRC family kinases and receptor tyrosine kinases by dasatinib: Possible combinations in solid tumors. Clin Cancer Res 17: 5546-5552, 2011.

42. Rebas E and Lachowicz-Ochedalska A: The effect of angiotensin III on protein tyrosine kinase activity in rat pituitary. Regul Pept 130: 14-18, 2005. 
43. Lewandowska U, Lachowicz-Ochedalska A, Domińska K, Kaszewska D and Rębas E: Angiotensin II as a factor modulating protein tyrosine kinase activity in two breast cancer lines -MCF-7 and MDA-MB-231. Endokrynol Pol 62: 151-158, 2011.

44. Reis AB, Araújo FC, Pereira VM, Dos Reis AM, Santos RA and Reis FM: Angiotensin (1-7) and its receptor Mas are expressed in the human testis: Implications for male infertility. J Mol Histol 41: 75-80, 2010.

45. Uemura $\mathrm{H}$, Nakaigawa $\mathrm{N}$, Ishiguro $\mathrm{H}$ and Kubota $\mathrm{Y}$ : Antiproliferative efficacy of angiotensin II receptor blockers in prostate cancer. Curr Cancer Drug Targets 5: 307-323, 2005.

46. Chow L, Rezmann L, Catt KJ, Louis WJ, Frauman AG, Nahmias C and Louis SNS: Role of the renin-angiotensin system in prostate cancer. Mol Cell Endocrinol 302: 219-229, 2009.
47. Pawlikowski M, Minias R, Sosnowski M and Zieliński KW: Immunohistochemical detection of angiotensin AT 1 and AT 2 receptors in prostate cancer. Cent European J Urol 64: 252-255, 2011.

48. Waters C, Pyne S and Pyne NJ: The role of G-protein coupled receptors and associated proteins in receptor tyrosine kinase signal transduction. Semin Cell Dev Biol 15: 309-323, 2004.

49. Chow L, Rezmann L, Imamura K, Wang L, Catt K, Tikellis C, Louis WJ, Frauman AG and Louis SN: Functional angiotensin II type 2 receptors inhibit growth factor signaling in LNCaP and PC3 prostate cancer cell lines. Prostate 68: 651-660, 2008. 